\title{
AS MÍDIAS DIGITAIS NA PRÉ-ESCOLA: UMA ANÁLISE A PARTIR DA BASE NACIONAL COMUM CURRICULAR (BNCC)
}

\author{
THE DIGITAL MEDIA IN THE PRE-SCHOOL: AN ANALYSIS FROM THE COMMON \\ NATIONAL CURRICULAR BASE (BNCC)
}

\author{
Jonathas Fontes Santos \\ Mestre em Educação, Universidade Tiradentes - UNIT \\ Aracaju, SE - Brasil \\ jonathasfontes@hotmail.com \\ Cristiane de Magalhães Porto \\ Doutora, Universidade Tiradentes - UNIT \\ Instituto de Tecnologia e Pesquisa -ITP \\ Aracaju, SE - Brasil \\ crismporto@gmail.com
}

\author{
Isabella Silva dos Santos \\ Mestra, Secretaria de Educação e Cultura do Estado de Sergipe - SEDUC \\ Aracaju, SE - Brasil \\ profeisabellaufs@gmail.com
}

\begin{abstract}
Resumo: $\mathrm{O}$ artigo defende que a pré-escola se aproxime das inclinações e oportunidades intrínsecas às mídias digitais. O objetivo é analisar se intentos na Base Nacional Comum Curricular (BNCC) corroboram com esse movimento aproximativo. Para isso, num movimento reflexivo discute-se sobre as 'competências gerais', os 'direitos de aprendizagem e desenvolvimento' e os 'campos de experiências' definidos na BNCC, com intuito de perceber possíveis aproximações entre a Educação Infantil (EI) e o contexto das mídias digitais. Constata-se que há uma relação paradoxal na BNCC entre aquilo que as competências gerais recomendam acerca das mídias digitais para toda a Educação Básica e aquilo que é proposto na própria base nacional, especificamente, para a EI. Paradoxos nesse sentido só fortalecem ainda mais o distanciamento existente entre a pré-escola e as mídias digitais em suas oportunidades e inclinações. Com isso, conclui-se que um movimento de aproximação entre pré-escola e mídias digitais demanda esforços investigativos que contraponham o distanciamento que ainda persiste na contemporaneidade.
\end{abstract}

Palavras-chave: Cibercultura. Educação básica. Infância.

Abstract: The article argues that the preschool approach the inclinations and opportunities intrinsic to digital media. The objective is to analyze if attempts at the Base Nacional Comum Curricular (BNCC) corroborate this approximate movement. For this, a reflexive movement is discussed about the 'general competences', the 'learning and development rights' and the 'field experiences' defined in the BNCC, in order to perceive possible approximations between Early Childhood Education (EI) and context of digital media. There is a paradoxical relationship in BNCC between what general competences recommend about digital media for all Basic Education and what is proposed in the national base itself, specifically, for IE. Paradoxes in this sense only further strengthen the gap between preschool and digital media in their opportunities and inclinations. With this, it is concluded that a movement of approximation between preschool and digital media demands investigative efforts that oppose the distance that persists in contemporaneity.

Keywords: Cyberculture. Basic education. Childhood.

Para citar - (ABNT NBR 6023:2018)

SANTOS, Jonathas Fontes; PORTO, Cristiane de Magalhães; SANTOS, Isabella Silva dos. As mídias digitais na pré-escola: uma análise a partir da Base Nacional Comum Curricular (BNCC). Eccos - Revista Científica, São Paulo, n. 56, p. 1-15, e13436, jan./mar. 2021. Disponível em: https://doi.org/10.5585/eccos.n56.13436. 


\section{Introdução}

As crianças como seres sociais costumam chegar à pré-escola marcadas por experiências vivenciadas com as mídias digitais, por estas intercambiarem formas simbólicas que oportunizam diversão, comunicação, desejo, consumo, aprendizado etc. Como produtoras de cultura, elas têm nessas mídias formas de constituir seus círculos de relações diante da sociedade plural em que vivem.

Os contextos socioculturais extraescolares propiciam a elas vivências que diferem muito do que as instituições educacionais comumente oferecem. Quando se dialoga com crianças em idade pré-escolar sobre suas explorações ou compreensões acerca das mídias digitais, elas sentem-se instigadas a partilhar percepções e vivências com os artefatos tecnológicos em seus cotidianos.

Conversas nesse sentido levam à constatação de que muitas utilizam jogos digitais; assistem a audiovisuais via streaming; comunicam-se por aplicativos mobiles etc. Daí, a anuência de que existam implicações no âmbito pré-escolar para as propostas e práticas educacionais. Abre-se então um horizonte de possibilidades reflexivas, a exemplo, das questões culturais, que na contemporaneidade encontram-se eivadas de oportunidades e inclinações tecnológicas decorrentes das mídias digitais.

Compreende-se com isso que as crianças se contextualizam a essas oportunidades e inclinações, o que incide sobre a função social da pré-escola considerar o fenômeno digital. Desse modo, entende-se que o atual cenário cultural reclama que questões políticas sejam revisitadas, a exemplo das políticas educacionais.

Analisa-se então as 'competências gerais' definidas na Base Nacional Comum Curricular (BNCC) para identificar suas recomendações acerca das mídias digitais e seguidamente verificar se os 'direitos de aprendizagem e desenvolvimento' e os 'campos de experiências’ propostos para a Educação Infantil (EI) articulam-se com o cenário digital.

A ideia fundante do estudo é de que as formas simbólicas produzidas e intercambiadas pelas mídias digitais tencionam implicações no contexto pré-escolar. A partir disso, o texto aporta-se na teoria sociológica da mídia proposta por Thompson (2013) e por isso reconhece a pré-escola como uma instituição estabilizada a partir de dispositivos legais e sociais em regras, recursos e relações. Ademais, reconhece o distanciamento entre a cultura escolar e a popular (BUCKINGHAM, 2006).

Assente-se assim, um movimento reflexivo pelo qual se explicita inicialmente o contexto em linhas gerais das transformações instauradas com as mídias digitais na vida social. 
Logo após, apresenta os conceitos fundantes aportados na teoria sociológica da mídia, os quais sustentam as reflexões seguintes acerca da aproximação aqui defendida, a de uma pré-escola que considera em sua atuação as possibilidades digitais. Com intenção desmistificadora, expõe ainda uma pesquisa portuguesa de modo a contrapor supostos riscos atribuídos às práticas préescolares que exploram as mídias digitais. Para só então, refletir sobre as aproximações e distanciamentos da $\mathrm{BNCC}$ em relação às tais possibilidades.

Em desfecho, constata-se que a BNCC ao propor as competências gerais anuncia preocupações em articular a construção do conhecimento, o desenvolvimento de habilidades e a formação de atitudes e valores inerentes às mídias digitais, o que aproxima suas propostas curriculares do universo digital. Por outro lado, quando define suas diretrizes específicas para a EI em termos de 'direitos de aprendizagem e desenvolvimento' e os 'campos de experiências', distancia-se da preocupação explícita nas competências gerais.

\section{As mídias digitais em contextos pré-escolares}

As mídias digitais são parte da transformação profunda e irreversível daquilo que é aspecto central da vida social, a produção e o intercâmbio simbólico da sociedade. Na contemporaneidade, elas mostram-se como vetores recentes da reelaboração do caráter simbólico da vida social, da reorganização dos meios onde se produz e por onde se intercambiam símbolos e da reestruturação dos meios por onde os indivíduos se relacionam entre si (THOMPSON, 2013).

Considera-se como mídias digitais nesse estudo, aquelas que engendram

[...] o desenvolvimento de novas formas de informação baseadas em sistemas de codificação digital e gradual convergência da tecnologia de informação e comunicação para um sistema digital comum de transmissão, processamento e armazenamento (THOMPSON, 2013, p. 115).

Partir de um olhar para as crianças conforme as concepções teórico-sociológica da mídia (THOMPSON, 2013) é reconhecê-las como indivíduos que interpretam formas simbólicas e se apropriam de conteúdos que lhes são significativos. Assim, participam das reelaborações, reorganizações e reestruturações provocadas pelas mídias digitais.

Por conseguinte, a pré-escola precisa compreender que com isso o cotidiano das crianças se ressignifica constantemente. Para assim, opor-se ao contraste abordado por Buckingham (2006), de distanciamento entre a cultura escolar e a popular, especialmente, no que diz respeito às experiências infantis oportunizadas pelas mídias digitais e desconsideradas pelas pré-escolas. 
Nesse contexto de distanciamento, já se apontou que "a cultura digital desafia também a escola de educação infantil a superar os paradoxos existentes entre a cultura escolar e a das crianças imersas no mundo digital" (SANTOS, 2018, p. 160), já que a

[...] mídia digital apresenta à escola dilemas do tipo, na medida em que precisa olhar para a cultura digital em razão do papel, cada vez mais significativo desempenhado por ela; por outro, precisa considerar as desigualdades de acesso às tecnologias digitais, as quais transcendem o acesso físico (SANTOS, 2018, p. 153).

Estudos no país apresentam contribuições com intuito de aproximar esse espaço escolar das inclinações e oportunidades dessas mídias. E para isso, analisam a percepção dos docentes quanto à relação entre pré-escola e tecnologias digitais (CHAMORRO, 2015; NOVAK, 2014); o brincar em contextos digitais (MENEGUZZO, 2014); a apropriação do computador na préescola (CAMARGO, 2013); a comunicação digital entre pré-escola e família (SILVA, 2017); as potencialidades que esse cenário tecnológico possa oportunizar na aquisição de leitura (NASCIMENTO, 2015); as maneiras de ser criança e viver a infância na contemporaneidade (MULLER, 2014); a alfabetização (MACHADO, 2014); o desenvolvimento de aplicativos infantis (DEMARCHI, 2015); além da influência da mídia e da multimídia no brincar infantil (CANASSA, 2013).

Logo, emerge no contexto das mídias digitais a necessidade de articulação entre a função da pré-escola com as oportunidades e inclinações decorrentes das mídias digitais. Isto porque, fora da escola as crianças dispõem de distintas atividades com essas mídias, enquanto que no espaço escolar, quando não lhes negam, oferecem-nas sem que uma intencionalidade educativa tenha sido previamente compreendida e planejada.

Nas escolas muitas das iniciativas de usos mostram-se desinteressantes, dentre outros motivos, em razão das limitações impostas às crianças. Embora Buckingham (2006) reconheça existir justificativas para algumas delas, não se surpreende que as proibições provoquem aborrecimentos e tédio nos indivíduos. As experiências proporcionadas pela escola, quando comparadas às vivências externas, perdem espaço pelos poucos estímulos oferecidos em atratividade e emoção.

A reflexão que se propõe com o estudo advém dessa demanda educacional, a de se aproximar a cultura escolar daquela que as crianças vivem nos contextos não educacionais. Para isso, inicialmente, há um reconhecimento de que como indivíduos que compõem a vida social, as crianças "perseguem fins e objetivos os mais variados, [...] sempre agem dentro de um conjunto de circunstâncias previamente dadas que proporcionam a diferentes indivíduos inclinações e oportunidades" (THOMPSON, 2013, p. 37). 
A partir dessa concepção, têm-se as mídias digitais como um desses conjuntos capazes de oportunizar às crianças variados fins e objetivos. Esses conjuntos de circunstâncias são conceituados como 'campos de interação', onde a criança ou qualquer outro indivíduo pode situar-se em diferentes posições, as quais dependem dos recursos que lhe sejam acessíveis.

Depois de estabilizadas, as posições "tornam-se parte de um conjunto relativamente estável de regras, recursos e relações sociais” (THOMPSON, 2013, p. 37). Daí se definir uma instituição como um "conjunto de regras, recursos e relações com certo grau de durabilidade no tempo e alguma extensão no espaço, e que se mantém unidas com o propósito de alcançar alguns objetivos globais" (THOMPSON, 2013, p. 37).

A posição que um indivíduo ocupa dentro de um campo ou instituição é muito estreitamente ligada ao poder que ele ou ela possui. No sentido mais geral, poder é a capacidade de agir para alcançar os próprios objetivos ou interesses, a capacidade de intervir no curso dos acontecimentos e em suas consequências. No exercício do poder os indivíduos empregam os recursos que lhe são disponíveis; recursos são os meios que lhes possibilitam alcançar efetivamente seus objetivos e interesses. (THOMPSON, 2013, p. 38).

As crianças integram e ocupam posições em outros campos de interação cujas posições já foram historicamente institucionalizadas, em razão de anteriores estabilizações em 'regras', 'recursos' e 'relações sociais', a exemplo da posição como alunos da pré-escola. Este espaço institucionalizado se concebeu historicamente a partir de lutas sociais e demandas de setores populares (relações sociais), que culminaram em dispositivos legais (regras) asseguradores da EI como dever do Estado e direito social (KUHLMANN, 2015).

Para efetivação dos objetivos garantidos pelos dispositivos legais instauradores da EI no Brasil, essas instituições devem contemplar condições para o exercício de suas atividades. As Diretrizes Curriculares Nacionais para a Educação Infantil (DCNEI) fixadas pela Resolução $N^{\circ} 5$ de 17 de dezembro de 2009 orientam quanto à organização de espaço, tempo e materiais (recursos), indispensáveis ao alcance dos objetivos próprios da pré-escola.

Posteriormente, consolida-se em 2018 no país a BNCC, documento de caráter normativo surgido com intuito de definir

[...] o conjunto orgânico e progressivo de aprendizagens essenciais que todos os alunos devem desenvolver ao longo das etapas e modalidades da Educação Básica, de modo a que tenham assegurados seus direitos de aprendizagem e desenvolvimento, em conformidade com o que preceitua o Plano Nacional de Educação (PNE) (BRASIL, 2018, p. 7).

As mídias digitais permitem a produção e o intercâmbio de formas simbólicas pelos indivíduos, a exemplo das crianças. Ao interpretar essas formas as crianças apropriam-se do 
que lhes asseguram significados e assim criam circunstâncias que desafiam a pré-escola a considerar essas mídias em inclinações e oportunidades.

Por caber às instituições pré-escolares “[definir] a configuração dos campos de interação preexistentes e, ao mesmo tempo, [criar] novas posições dentro deles. Bem como, novos conjuntos de trajetórias de vida para os indivíduos que os ocupam" (THOMPSON, 2013, p. 37). É preciso que elas criem com as mídias digitais campos de interação nesse sentido, para garantir a participação em campos que transcendam as posições tradicionais.

A possibilidade de criação pela pré-escola sob esse olhar implica redefinições naquilo que a compõe (regras, recursos e relações). A exemplo, de se redefinir suas propostas curriculares, de igual modo, de articular mudanças nas políticas educacionais instituídas em diferentes esferas. Por outro lado, compreende-se também que além dessas redefinições curriculares, a aproximação aqui defendida tem outro desafio, desmistificar críticas que "centram-se em redor de um conjunto de "riscos" para o desenvolvimento emocional, social e cognitivo das crianças" (AMANTE, 2007, p. 2).

Uma pesquisadora portuguesa discute algumas dessas visões, na tentativa de desmistificá-las. E diferente do que pensam alguns críticos, para Amante (2007), por exemplo, a inserção de tecnologias digitais em salas pré-escolares não diminui o uso dos materiais tradicionais, nem a procura das crianças por outras atividades, pelo contrário, pode promover um 'efeito novidade' e gerar entusiasmo.

Igualmente, contesta a ideia de que crianças menores de 7 anos são desprovidas de condições para operarem com sistemas abstratos, salientando que a necessidade fundamental é de experiências diretas com o mundo envolvente. Sua objeção é que "as crianças pequenas se mostram confortáveis e confiantes [...] e revelam várias competências [...], o que não indicia que tenham dificuldade em operar com a [...] linguagem simbólica” (AMANTE, 2007, p. 3).

Críticas no sentido de que há suposto isolamento social em relação ao uso das mídias digitais pelas crianças são refutadas pela autora ao argumentar que,

[...] os computadores têm demonstrado não só não isolar as crianças como parecem constituir-se como catalizadores da interacção e do trabalho colaborativo criando oportunidades acrescidas para o desenvolvimento de competências sociais e cognitivas (AMANTE, 2007, p. 4).

Em sua convicção, dispositivos digitais 
[...] não tomam pois o lugar da interação humana, nem a substituem, podendo antes contribuir para a estimular [...] o incremento do diálogo e da cooperação entre as crianças, a partilha de papéis de liderança, a tutoria mútua entre pares e a iniciação de interações e pedidos de ajuda mais frequentes em redor das actividades desenvolvidas com recurso ao computador [...], especialmente quando os programas utilizados têm características abertas e apelam a resolução de problemas (AMANTE, 2007, p. 4).

Ao desnudar o lapso cometido por alguns autores de que crianças diante de mídias digitais se transformam em autômatas e passivas, as quais se comportam 'como uma máquina de dar respostas", e por isso interferem "negativamente no desenvolvimento da sua afectividade e da sua criatividade" (AMANTE, 2007, p. 5). A autora argumenta que:

Efectivamente muita coisa mudou e naturalmente que muitas das coisas a que as
crianças hoje têm acesso, quer para brincar, quer para aprender, são diferentes
daquelas a que tínhamos acesso quando éramos nós crianças. Contudo, o facto natural
de valorizarmos muito as vivências da nossa infância, não nos pode levar a confundir
as coisas, ou seja, a achar que a nossa infância foi mais rica afectivamente do que a
das crianças do início deste século, nem muito menos achar que isso se deve aos novos
artefactos tecnológicos.
[...] a primeira coisa que nos ocorre perguntar é se a Escola, antes de existirem os
computadores, era criativa. Quantos de nós poderemos dizer que aprendemos de uma
forma criativa? (AMANTE, 2007, p. 5).

Em contrapartida, reconhece que é inerente ao uso de dispositivos digitais o risco de pautar-se também em formas não criativas e com isso reduzir a criatividade das crianças. Isto se dá, por exemplo, quando são utilizados

[...] para explorar programas de exercício e prática (drill and practice software), mas os resultados mostram também que o mesmo não acontece quando as crianças utilizam software aberto (open-ended) adequado ao seu desenvolvimento. (AMANTE, 2007, p. 5).

Então, quanto ao lapso da criatividade, seu reconhecimento é de que as utilizações de forma criativa de mídias digitais pelas crianças não depende dos dispositivos, mas das experiências que lhes são proporcionadas em contextos pré-escolares. São estas que podem facilitar o desenvolvimento, possibilitar uma utilização ativa e criativa, e superar as posições de simples consumidoras e de passividade diante da cultura popular.

Coube ainda a Amante contestar os argumentos contrários ao uso dessas mídias pela pré-escola dirigidos às preocupações com a saúde da criança. Entre essas visões elencam-se afirmações do tipo, 'elas provocam tensões nervosas', 'afetam a visão' e 'promovem um estilo de vida sedentário'. Com cautela em sua abordagem, por não existir, segundo ela, investigações suficientes que as comprovem ou neguem, no âmago de suas reflexões aponta para a necessidade de se considerar a relação adversa entre o contexto familiar e o educacional. 
Aspectos como tempo de utilização e comportamentos de dependência são considerados em suas ponderações. Também mostra uma potencialidade das tecnologias em termos de saúde. Quanto ao fator de utilização, explica que,

[...] se a tecnologia for utilizada por períodos de tempo prolongados, naturalmente que esta questão se colocará com maior pertinência, mas este risco não se coloca ao nível dos contextos de escola e jardim de infância, ou outros contextos formais de aprendizagem, dizendo sobretudo respeito ao contexto mais global de utilização dos media, designadamente aos contextos familiares em que a tecnologia, seja ela na forma de computadores, consolas, leitores de DVD ou televisão, está presente e tende a preencher grande parte dos tempos livres das crianças. (AMANTE, 2007, p. 6).

Por outro lado, coloca-se a preocupação quanto ao possível desenvolvimento de comportamentos de dependência face ao uso dessas tecnologias, designadamente os jogos. Reflete ela que este problema se situa, no entanto,

[...] essencialmente, fora do contexto escolar, em populações adolescentes e deve ser encarado não como um problema provocado pela tecnologia em si, mas como uma manifestação de problemas, ou potenciais problemas de enquadramento familiar e social (AMANTE, 2007, p. 6).

Em contrapartida, finaliza a questão da saúde com a demonstração de uma potencialidade descoberta a partir de jogos digitais. Ela faz referência a uma pesquisa sobre a utilização de jogos interativos como formas de desempenhar um papel importante de ajuda às crianças que precisam compreender a patologia e os cuidados médicos necessários e com isso melhorarem suas atitudes face a uma doença, mudando assim, seus comportamentos.

Outra abordagem de Amante é sobre um conjunto de problemas éticos e morais quanto à utilização da Internet por crianças. Por exemplo, o acesso aos conteúdos inapropriados (pornografia, violência etc.), a conflitante relação entre o que venha ser informação e publicidade, a violação de privacidade, e ainda, os riscos em manter através da rede contatos com estranhos.

Sua defesa é de que "estes riscos devem ser vistos como dilemas que devem ser resolvidos, mas não como razão para [negar] às crianças uma experiência que pode e deve ser de grande relevância" (AMANTE, 2007, p. 7). Assim, as oportunidades e inclinações abertas pelos campos de interações nas mídias digitais em contextos pré-escolares demandam esforços de enfrentamento às negatividades, é comum estas serem mais visíveis que aquelas.

As crianças nascidas na ambiência social da cultura contemporânea vivem a conectividade e experimentam novas formas de interação, de brincar e de consumir. Essas experiências convidam-nas a uma vivência cercada por artefatos tecnológicos capazes de 
atender às demandas postas pelas reconfigurações da cultura infantil diante das mídias digitais. Como afirma, Serres (2013) elas 'habitam o virtual'.

Essa participação ativa diante das mídias digitais dar-se, sobretudo, por meio das tecnologias móveis (COUTO, 2013), pois esses artefatos tornaram-se significativos na vida infantil. Dedos são arrastados em tablets e smartphones e conduzem as crianças a diversas narrativas, interações com games, produção e compartilhamento de conteúdo, em suma "participando efetivamente desse universo tecnológico" (ALVES; TORRES, 2017, p. 61).

Nesses termos, é que se analisa a seguir, a BNCC em suas 'competências gerais', ‘direitos de aprendizagem e desenvolvimento' e 'campos de experiências', e enquanto as competências analisadas contemplam em sua abrangência toda a Educação Básica, os últimos são específicos para a EI. A análise percorre um caminho contextualizado às mídias digitais em suas oportunidades e inclinações, quanto à produção e intercâmbio de formas simbólicas.

\section{Análise da bncc no contexto da pré-escola e das mídias digitais}

A educação configura-se num dos direitos sociais assegurados pela Constituição Federal de 1988 e àqueles que visem melhorias em suas condições sociais reserva-lhes o direito de assistência gratuita aos filhos ou dependentes com até 5 anos de idade em creches e préescolas. Como direito de todos e dever do Estado, a educação efetiva-se a partir de garantias, dentre elas a de EI oferecida por essas instituições.

A BNCC surge como referência nacional para a formulação dos currículos e propostas pedagógicas, e ainda para contribuir com outras políticas e ações que se vinculem "à formação de professores, à avaliação, à elaboração de conteúdos educacionais e aos critérios para a oferta de infraestrutura adequada para o pleno desenvolvimento da educação" (BRASIL, 2018, p. 8).

As 'aprendizagens essenciais' definidas pela BNCC devem concorrer ao longo da Educação Básica “para assegurar aos estudantes o desenvolvimento de dez competências gerais, que consubstanciam, no âmbito pedagógico, os direitos de aprendizagem e desenvolvimento" (BRASIL, 2018, p. 8). Três das competências relacionam-se diretamente com o que se pretende analisar, são elas: 
1. Valorizar e utilizar os conhecimentos historicamente construídos sobre o mundo físico, social, cultural e [digital] para entender e explicar a realidade, continuar aprendendo e colaborar para a construção de uma sociedade justa, democrática e inclusiva.

$[\ldots]$

4. Utilizar diferentes linguagens - verbal (oral ou visual-motora, como Libras, e escrita), corporal, visual, sonora e [digital] -, bem como conhecimentos das linguagens artísticas, matemática e científica, para se expressar e partilhar informações, experiências, ideias e sentimentos em diferentes contextos e produzir sentidos que levem ao entendimento mútuo.

5. Compreender, utilizar e criar [tecnologias digitais] de informação e comunicação de forma crítica, significativa, reflexiva e ética nas diversas práticas sociais (incluindo as escolares) para se comunicar, acessar e disseminar informações, produzir conhecimento, resolver problemas e exercer protagonismo e autoria na vida pessoal e coletiva (BRASIL, 2018, p. 9).

Essas e as demais competências definidas pela BNCC

[...] inter-relacionam-se e desdobram-se no tratamento didático proposto para as três etapas da Educação Básica (Educação Infantil, Ensino Fundamental e Ensino Médio), articulando-se na construção de conhecimentos, no desenvolvimento de habilidades e na formação de atitudes e valores (BRASIL, 2018, p. 8).

Consequentemente, entende-se que no tratamento didático proposto pela BNCC para a EI os conhecimentos historicamente construídos sobre o mundo digital precisam ser valorizados e utilizados, de maneira que contribuam com o entendimento e explicação da realidade. E, similarmente, que haja a continuidade da aprendizagem e a colaboração na construção de uma sociedade justa, democrática e inclusiva.

Espera-se ainda a utilização da linguagem digital como uma das possibilidades para que as crianças se expressem e partilhem informações, experiências, ideias e sentimentos, e possam produzir sentidos passíveis de entendimento mútuo. No entanto, cada um dos aspectos intrínsecos ao tratamento demanda compreensão das tecnologias digitais.

Dito isso, precisa-se mencionar que as competências se tornam no decorrer da estruturação da BNCC uma expressão dos seis direitos de aprendizagem e desenvolvimento pelos quais se espera que as crianças da EI tenham condições de aprender e se desenvolver, são eles: Conviver, Brincar, Participar, Explorar, Expressar e Conhecer-se.

Essas condições para aprender e se desenvolver são complementadas pela BNCC com o estabelecimento de cinco campos de experiências: $\mathrm{O}$ eu, o outro e o nós; Corpo, gestos e movimentos; Traços, sons, cores e formas; Escuta, fala, pensamento e imaginação e Espaços, tempos, quantidades, relações e transformações. Para os campos define-se os objetivos de aprendizagem e desenvolvimento que se organizam por faixa etária em três grupos: Bebês (01a6m), Crianças bem pequenas (1a7m-3a11m) e Crianças Pequenas (4a-5a11m). 
Embora se constate nas competências gerais a explicitação direta do termo digital, referindo-se ao 'mundo digital', à 'linguagem digital' e às 'tecnologias digitais', competências as quais deveriam configurar-se numa expressão dos direitos de aprendizagem e desenvolvimento definidos pela BNCC, no âmbito da primeira etapa da Educação Básica não se percebe tal ocorrência, ao analisar esses direitos.

Como exemplo, evidencia-se no documento normativo uma lacuna ao explicar o direito do Brincar, por não refletir as definições das competências gerais que envolvem o contexto digital, pois sequer menciona-se alguma relação lúdica entre o direito e os termos explicitados claramente nas competências (mundo digital, linguagem digital ou tecnologias digitais). Ainda que, o brincar na cultura contemporânea seja passível de múltiplos processos interativos e vivências infantis num "hibridismo de práticas e descobertas lúdicas" (COUTO, 2013, p. 908) em que tocar telas e brincar se mostram como sinônimos.

Acerca do Explorar aponta-se os aspectos passíveis de exploração na escola e fora dela, de modo que venha ampliar os saberes sobre a cultura em suas diversas modalidades incluindose nestas, a tecnologia. Logo depois, o direito de Expressar é posto como aquele em que a criança pode exercê-lo por meio de diferentes linguagens.

$\mathrm{O}$ reconhecimento defendido nesse texto é de que para fomentar correlações entre os direitos e as competências no que tange às mídias digitais, a BNCC deveria incluir diretamente algumas das possíveis relações, como se faz com o Explorar e o Expressar, ao trazer os termos 'tecnologia' e 'linguagem'. Os quais asseguram contemplação, respectivamente, das tecnologias digitais e da linguagem digital.

Não são apenas os direitos de aprendizagem e desenvolvimento que se negam a trazer relações diretas com as competências gerais, naquilo que estas consideram as mídias digitais. Afinal, os campos de experiências que se propõem constituírem "um arranjo curricular que acolhe as situações e as experiências concretas da vida cotidiana das crianças e seus saberes entrelaçando-os aos conhecimentos que fazem parte do patrimônio cultural" (BRASIL, 2018, p. 38), do mesmo modo, são omissos nesse sentido.

O primeiro campo ' $\mathrm{O}$ eu, o outro e o nós' enfatiza um tipo de interação das crianças da EI com os pares e com os adultos, ao que se denota uma priorização unicamente do tipo de interação face a face, e assim perde-se de vista as potencialidades interativas das mídias digitais. O que se compreende da análise não é que se deva prevalecer as oportunidades digitais sobre o tipo de interação face a face, mas que ao menos as apontem como pertinentes à educação na contemporaneidade. 
Por outro lado, esse campo define que "é preciso criar oportunidades para que as crianças entrem em contato com outros grupos sociais e culturais, outros modos de vida, diferentes atitudes, técnicas e rituais de cuidados pessoais e do grupo, costumes, celebrações e narrativas" (BRASIL, 2018, p. 38). Criações nesses termos, embora não sejam explicitadas, são passíveis de se despertar aberturas capazes de oportunizar às crianças experiências por meio das mídias digitais e conceder aos indivíduos da pré-escola ocupações em campos de interações mediados pelo digital.

Ao avançar para o campo de experiência 'Escuta, fala, pensamento e imaginação' percebe-se uma preocupação centrada na cultura escrita. Isso, na medida em que contextualiza as experiências da criança no contexto familiar, comunitário e escolar como um indivíduo que de modo simplista só constrói uma concepção de língua escrita e reconhece seus usos sociais.

Diante disso, o que se nota é uma desconsideração de que as crianças na cultura contemporânea também constroem concepções acerca de outras linguagens diferentes da escrita, a exemplo daquelas presentes nas produções e intercâmbios de formas simbólicas das mídias digitais. Acrescente-se ainda, conforme aponta Martín-Barbero (2013, p. 125), que a “escrita digital é hoje um direito primário do exercício de cidadania para o qual a escrita escolar não prepara". Portanto, até a própria escrita enaltecida pelo campo de experiência é passível de consideração dessas mídias

Por fim, ao mencionar haver na criança uma manifestação de curiosidade, o campo de experiência em análise pontua apenas aquela que se relaciona à cultura escrita, como se na cultura contemporânea em que as reconfigurações são constantes em meio às transformações tecnológicas, a curiosidade não fosse instigada nas crianças também via uma cultura digital.

\section{Considerações}

Pensar a pré-escola no Brasil diante do que as crianças têm experimentado com as mídias digitais demanda considerar as transformações quanto àquilo que foi reelaborado, reorganizado e reestruturado por essas mídias na vida social. Porquanto, as implicações que incidem em várias áreas da sociedade, na qual a educacional não se exime, desafia inclusive o nível pré-escolar.

Diante das definições estabelecidas pela BNCC percebe-se que três das competências gerais defendem uma aproximação da Educação Básica a essas transformações. Contrariamente, os 'direitos de aprendizagem e desenvolvimento' e os 'campos de 
experiências', que se dirigem especificamente para a ação educativa na EI, são omissos em estabelecer relações similares, conforme se nota nas competências gerais.

Constata-se, inicialmente, que os direitos de aprendizagem e desenvolvimento que juntos deveriam corroborar acerca das mídias digitais com as competências gerais não concebem apontamentos situados nas possibilidades digitais. Omissão que, de igual modo, se repete nos campos de experiências, quando também não as explicitam.

Por fim, entende-se que a BNCC concebe em três de suas competências gerais, marcas de uma tentativa de aproximação entre a cena educacional e as mídias digitais. Contudo, naquilo que é específico à EI, os 'direitos de aprendizagem e desenvolvimento' e os 'campos de experiências' analisados, distanciam-se desse movimento aproximativo. Vê-se isso como algo paradoxal, ou seja, entre o que se concebe em âmbito geral e aquilo que se define para a primeira etapa da Educação Básica.

Por isso, é que se conclui que o movimento de aproximação entre a pré-escola e as mídias digitais, continua a demandar esforços investigativos. Inclusive, no sentido de superar não apenas esse, mas semelhantes paradoxos que se expressam nas políticas educacionais. Com isso, pode-se contrapor os persistentes distanciamentos entre as práticas pré-escolares e as realidades digitais cotidianamente vividas pelas crianças.

\section{Referências}

AMANTE, Lúcia - Infância, escola e novas tecnologias. In Costa, Fernando Albuquerque; Peralta, Helena; Viseu, Sofia, org. - "As TIC na educação em Portugal [Em linha] : concepções e práticas. Porto : Porto Editora, 2007, p. 102-123.

ALVES, Lynn; TORRES, Velda (Org.). Jogos digitais, entretenimento, consumo e aprendizagens: uma análise do Pokémon Go. Salvador: Edufba, 2017.

BRASIL. Ministério da Educação. Secretaria de Educação Básica. Diretrizes curriculares nacionais para a educação infantil. Brasília: 2010. Disponível em:

http://ndi.ufsc.br/files/2012/02/Diretrizes-Curriculares-para-a-E-I.pdf. Acesso em: 23 out 2018.

BRASIL. Ministério da Educação. Secretaria de Educação Básica. Base Nacional Comum Curricular. Brasília: 2018. Disponível em: http://basenacionalcomum.mec.gov.br/wpcontent/uploads/2018/02/bncc-20dez-site.pdf. Acesso em: 04 dez 2018.

CANASSA, L. M. R. Infância, TIC e Brincadeiras: um estudo na visão de profissionais da educação infantil: desafios da geração homo zappiens. 2013. Dissertação (Mestrado em Educação) - Universidade do Oeste Paulista, Presidente Prudente. 
BUCKINGHAM, David. La educación para los medios en la era de la tecnología digital. In: Congreso del X aniversario de MED. 2006. Disponível em: http://files.tics-en-nuestrasaulas.webnode.com.uy/200000012-e2369e3301/ArtigoBuckingham.pdf. Acesso em: 9 nov 2018.

CHAMORRO, A. L. A educação musical infantil e o uso das tecnologias de informação e comunicação: percepção dos docentes. 2015. Dissertação (Mestrado em Educação) Universidade do Oeste Paulista, Presidente Prudente.

CAMARGO, M. B. C. A educação Infantil teclando e navegando na tecnologia da informação. 2013. Dissertação (Mestrado em Educação) - Universidade Estadual de Campinas, Faculdade de Educação, São Paulo.

Constituição da República Federativa do Brasil. Brasília, DF: Senado Federal, 1988.

COUTO, E. S. A infância e o brincar na cultura digital. Perspectiva, v. 31, n. 3, p. 897-916, 2013. Disponível em: https://periodicos.ufsc.br/index.php/perspectiva/article/view/2175-795X.2013v31n3p897; Acesso em: 4 nov 2018.

DEMARCHI, G. S. Potencializando a experiência da criança de educação infantil através da interface gráfica no ambiente de TVDi. 2015. Dissertação (Mestrado em Design) - Programa de Pós-Graduação em Design da Universidade Federal do Rio Grande do Sul, Porto Alegre.

KUHLMANN JUNIOR, Moysés. Infância e educação infantil: uma abordagem histórica. 7. ed. Porto Alegre: Mediação, 2015.

MARTIN-BARBERO, Jesús. A comunicação na educação. Tradução: Maria Immacolata Vassallo de Lopes e Dafne Melo. São Paulo: Contexto, 2014.

MACHADO, A. M. C. Tablets na educação infantil: tecnologia em sala de aula e seus benefícios para o processo de alfabetização. Dissertação (Mestrado em Gestão Educacional) - Programa de Pós-graduação em Gestão Educacional da Universidade do Vale do Rio dos Sinos, 2014.

MENEGUZZO, L. A. O brincar na educação infantil: a influência das tecnologias digitais móveis no contexto da brincadeira. 2014. Dissertação (Mestrado em Educação) Universidade de Caxias do Sul, Caxias do Sul.

MULLER, J. C. Crianças na contemporaneidade: representações e usos das tecnologias móveis na educação infantil. 2014. Dissertação (Mestrado em Educação) - Programa de PósGraduação da Universidade Federal de Santa Catarina, Florianópolis.

NASCIMENTO, M. S. A tecnologia da mesa educacional alfabeto a serviço da aquisição da leitura na educação infantil. 2015. Dissertação (Mestrado em Educação) - Programa de PósGraduação da Universidade Federal da Paraíba, João Pessoa.

NOVAK, E. C. A mídia digital e a relação com a criança da educação infantil: percepções dos professores sobre interatividade e processos comunicacionais. 2014. Dissertação 
(Mestrado em Comunicação e Linguagens) - Programa de Pós-Graduação da Universidade Tuiuti do Paraná, Curitiba.

SANTOS, J. F. A Cibercultura na Educação Infantil: possibilidades de des-reterritorializações. In: PORTO, Cristiane; ALVES, A. L; MOTA, M. F. (Org.). Educiber: Diálogos ubíquos para além da tela e da rede. Aracaju, EDUNIT, 2018. p. 149-161.

SILVA, A. P. R. Tecnologias Digitais como alternativas complementar à comunicação entre a família e a escola: um estudo na Educação Infantil. 2017. Dissertação (Mestrado) Programa de Pós-Graduação em Educação, Pontifícia Universidade Católica do Rio Grande do Sul, Porto Alegre.

SERRES, Michel. Polegarzinha. trad. Jorge Bastos. Rio de Janeiro: Bertrand Brasil, 2013.

THOMPSON, J. B. A mídia e a modernidade: uma teoria social da mídia. trad. Wagner de Oliveira Brandão; revisão da tradução Leonardo Avritzer. 14. ed. Petrópolis: Vozes, 2013. 